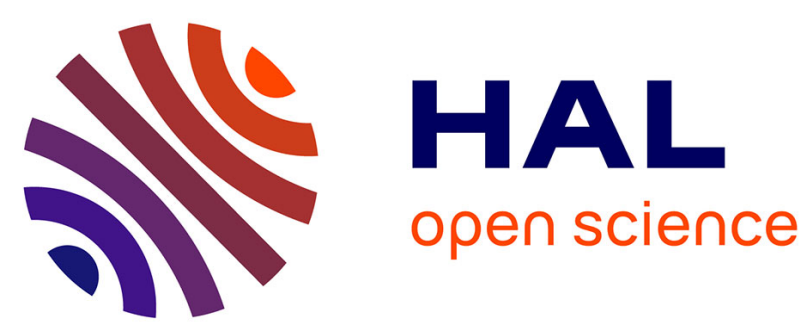

\title{
Effect of GaAs substrate orientation on the growth kinetic of GaN layer grown by MOVPE
}

\author{
J. Laifi, N. Chaaben, H. Bouazizi, Najla Fourati, C. Zerrouki, Y. El Gmili, A.
} Bchetnia, Jean-Paul Salvestrini, B. El Jani

\section{- To cite this version:}

J. Laifi, N. Chaaben, H. Bouazizi, Najla Fourati, C. Zerrouki, et al.. Effect of GaAs substrate orientation on the growth kinetic of GaN layer grown by MOVPE. Superlattices and Microstructures, 2016, 94, pp.30-38. 10.1016/j.spmi.2016.02.037 . hal-01277597

\section{HAL Id: hal-01277597 \\ https://hal.science/hal-01277597}

Submitted on 28 Jan 2022

HAL is a multi-disciplinary open access archive for the deposit and dissemination of scientific research documents, whether they are published or not. The documents may come from teaching and research institutions in France or abroad, or from public or private research centers.
L'archive ouverte pluridisciplinaire HAL, est destinée au dépôt et à la diffusion de documents scientifiques de niveau recherche, publiés ou non, émanant des établissements d'enseignement et de recherche français ou étrangers, des laboratoires publics ou privés.

\section{(ㄷ)(1) $\$$}

Distributed under a Creative Commons Attribution - NonCommercial| 4.0 International 


\title{
Effect of GaAs substrate orientation on the growth kinetic of GaN layer grown by MOVPE
}

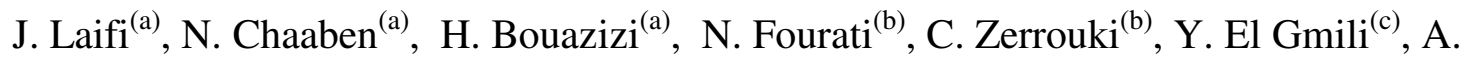 \\ Bchetnia $^{(a) *}$ J. P. Salvestrini ${ }^{(\mathrm{c}, d)}$ and B. El Jani ${ }^{(a)}$.
}

$\left({ }^{a}\right)$ Unité de Recherche sur les Hétéro-Epitaxies et Applications, Faculté des Sciences de Monastir 5019, Université de Monastir, Tunisia.

( $\left.{ }^{b}\right)$ SATIE, UMR 8029 CNRS-ENS Cachan-Cnam, 292 rue Saint-Martin, 75003, Paris, France.

\author{
${ }^{(c)}$ CNRS, UMI 2958 Georgia Tech - CNRS, 57070 Metz, France. \\ ${ }^{(d)}$ Université de Lorraine, Centrale Supelec, LMOPS, EA4423, 57070 Metz, France \\ *Corresponding authors. Tel: +216 73500 274; fax: +216 73500578.
}

E-mail address: amor.bchetnia@fsm.rnu.tn

\begin{abstract}
We have investigated the kinetic growth of low temperature GaN nucleation layers (LT$\mathrm{GaN}$ ) grown on GaAs substrates with different crystalline orientations. GaN nucleation layers were grown by metal organic vapor phase epitaxy (MOVPE) in a temperature range of 500$600^{\circ} \mathrm{C}$ on oriented (001), (113), (112) and (111) GaAs substrates. The growth was in-situ monitored by laser reflectometry (LR). Using an optical model, including time-dependent surface roughness and growth rate profiles, simulations were performed to best approach the experimental reflectivity curves. Results are discussed and correlated with ex-situ analyses, such as atomic force microscopy (AFM) and UV-visible reflectance (SR). We show that the $\mathrm{GaN}$ nucleation layers growth results the formation of $\mathrm{GaN}$ islands whose density and size vary greatly with both growth temperature and substrate orientation. Arrhenius plots of the growth rate for each substrate give values of activation energy varying from $0.20 \mathrm{eV}$ for the (001) orientation to $0.35 \mathrm{eV}$ for the (113) orientation. Using cathodoluminescence (CL), we also show that high temperature $\left(800-900^{\circ} \mathrm{C}\right) \mathrm{GaN}$ layers grown on top of the low temperature $\left(550^{\circ} \mathrm{C}\right) \mathrm{GaN}$ nucleation layers, grown themselves on the GaAs substrates with different orientations, exhibit cubic or hexagonal phase depending on both growth temperature and substrate orientation.
\end{abstract}

Keywords: High index GaAs, GaN, MOVPE, anisotropy, surface roughness. 


\section{Introduction}

GaN based optoelectronic devices have allowed high efficiency and high power light emitting diodes (LEDs) and lasers emitting in the UV to yellow spectrum [1, 2]. GaN can be crystallized in either hexagonal (wurtzite) or cubic (zinc blende) structure depending on both the substrate type and growth conditions. The hexagonal phase is generally obtained grown on substrates, such as sapphire and $6 \mathrm{H}-\mathrm{SiC}[3,4]$, while cubic GaN layers, which exibit higher carrier mobility and doping efficiencies [5-7] when compared to hexagonal GaN layers, can be grown on (001) GaAs [8], (001) Si [9] and 3C-SiC [10] substrates. In the case of the GaAs substrate, which is advantageous for device fabrication, both zinc blende and wurtzite phases may coexist in the GaN layer because of the small difference between formation of the different phases $[11,12]$. Nevertheless, cubic GaN layers with good crystalline and morphological qualities were obtained on GaAs (001) [13-15].

The possibility of changing and improving the fundamental material properties, growth mechanisms, surface kinetics and dopant incorporation by growing III-V semiconductors on substrates with crystallographic orientations other than (001) has motivated numerous studies [16-21]. In particular, semiconductor structures grown on high index substrates have fascinating properties, such as optical anisotropy [22], high hole mobility [23] and better optical efficiency [24], that cannot be found in similar structures grown on (001) oriented substrates. To our knowledge there are few investigations on the growth of $\mathrm{GaN}$ on high index GaAs substrates [25-29]. Makimoto et al [25] demonstrated that high-index surfaces are promising for the growth of GaN layers on GaAs substrate, and Sanorpim et al [27] found that GaAs (113) substrates help to grow better quality zinc blende GaN layers. Therefore, it is believed that $(11 \mathrm{n})$ surfaces would be promising for the growth of GaN layers on GaAs substrates.

The purpose of this work is thus to investigate the effects of GaAs substrate orientations on the nucleation of $\mathrm{GaN}$ at low growth temperature $\left(500-600^{\circ} \mathrm{C}\right)$, and then on the $\mathrm{GaN}$ layers overgrowth at high temperature $\left(800-900{ }^{\circ} \mathrm{C}\right)$. 


\section{Experimental details}

\subsection{Surface structure of GaAs substrates}

Fig.1 shows a schematic diagram of high-index (113), (112) and (111) planes of GaAs The corresponding tilt angles with respect to the (001) direction are $25.23^{\circ}, 35.26^{\circ}$ and $54.73^{\circ}$, respectively. The solid lines represent the (hkl) surfaces. The surface structure of the (112) and (113) planes are very similar, with components of both (001) and (111) bonding geometries. The surface structure of (112) is composed of periodic steps with one (001) terrace and two (111) atomic step edge, while the (113) surface is composed of equal numbers of (001) terrace and (111) atomic step edge.

\subsection{Growth conditions}

A first series of LT-GaN layers was grown by atmospheric pressure MOVPE in the temperature range of $500-600{ }^{\circ} \mathrm{C}$ on $(001),(111),(112)$ and (113) oriented semi-insulating GaAs substrates. At first, the GaAs substrates were exposed to a 2 slm (standard liter per minute) flow rate of ammonia $\left(\mathrm{NH}_{3}\right)$ for 10 minutes at a temperature of $550{ }^{\circ} \mathrm{C}$ for nitridation purpose. Then, Trimethylgallium (TMG) was introduced into the reactor to grow low temperature GaN layers. Hydrogen was used as a carrier gas with a flow rate of $2 \mathrm{slm}$. In order to avoid any difference in the growing procedure, the GaN layers were simultaneously grown on the four GaAs substrates. The growth was in-situ monitored by $\mathrm{He}-\mathrm{Ne}$ laser reflectometry $(\lambda=632.8 \mathrm{~nm})$ at normal incidence. Complementary ex-situ SR spectra were carried out for the measurements of thickness and growth rates. Surface morphologies of nitrided GaAs substrates and GaN nucleation layers were analyzed by AFM at a scale of ( $5 \mathrm{x}$ $5 \mu \mathrm{m}^{2}$ ). A second series of samples were prepared to study the overgrowth of GaN layers at HT $\left(800-900{ }^{\circ} \mathrm{C}\right)$ on top of the $130 \mathrm{~nm}$ thick LT-GaN nucleation layers. Room temperature CL investigations were performed in a digital scanning electron microscope to characterize the second series of samples. Emitted light is detected via a parabolic mirror collector and analyzed by a spectrometer with a focal length of $320 \mathrm{~mm}$ using a 1200 groove $\mathrm{mm}^{-1}$ grating and a spectral resolution of $0.06 \mathrm{~mm}$. The signal is then recorded by a liquid $\mathrm{N}_{2}$ - cooled Horiba Jobin Yvon Instruments Symphony 1024 x 256 CCD detector. 


\section{Results and discussion}

\subsection{Growth of LT-GaN layers}

Fig.2 shows AFM images of GaAs substrate surfaces after their nitridation. The substrate surfaces are characterized by island structures which are associated with GaN nucleus formation. The GaN nucleus density varies greatly with GaAs substrate orientation. The (001) surface presents the highest density of nucleus when compared to the other orientations. The (11n) surfaces are not completely covered by GaN nuclei whose spacing becomes bigger on these surfaces compared to that between the nuclei formed on (001). In particular, among these surfaces, (111) is the least covered surface, and shows isolated islands. The root-meansquare (rms) surface roughness of (001), (113), (112) and (111) nitrided GaAs substrates is estimated to be $6,14,10$ and $9 \mathrm{~nm}$, respectively. This difference could be related to the atomic bonds between $\mathrm{N}$ species and their adsorption sites in (hkl) GaAs surfaces which depend on dangling bond densities, step number on (11n) surfaces and surface energies [30-33].

Fig. 3 shows the experimental and simulated LR of LT-GaN nucleation layers grown at 550 ${ }^{\circ} \mathrm{C}$ on different GaAs substrate orientations. Before analyzing the simulations results, we present a qualitative study based on the LR characteristics such as the period and amplitude. When TMG is turned on $\left(t_{i}=0\right)$, the LR decreases and exhibits oscillations with constant amplitude versus time. These oscillations are the proof of the evolution of the GaN thickness resulting from growth and the fact that their amplitude are constant indicates that the surface roughness reaches a limit value, which does not depend on the layer thickness. The LR decrease can be associated with a weak surface roughness due to the nucleation. The largest LR oscillation amplitude is observed for the GaN/GaAs (001) growth indicating a weaker surface roughness in this case, likely due to the highest density of GaN nuclei formed on the nitrided GaAs (001) substrate. These nuclei act as nucleation sites in GaN layer, and thus enhance the coalescence of GaN islands and consequently improve the GaN surface quality. For GaN layers grown on high index GaAs substrates the surfaces are less reflecting, indicating rougher $\mathrm{GaN}$ surfaces which are associated with the low densities of GaN nuclei formed on all nitrided high index GaAs substrates. The lowest oscillation amplitude is obtained for GaN on GaAs (113) for which the value does not exceed $10 \%$ of the $R_{s}$ value.

To extract more information from the LR curves we used the following model. For rough surface film, the complex reflectance amplitude is expressed as follows [34, 35]: 


$$
r(t)=\frac{r_{12} \alpha(t)+r_{23}\left[\gamma^{2}(t)+r_{21}^{2}\left(\alpha(t) \beta(t)-\gamma^{2}(t)\right)\right] \exp \left(-\frac{i 4 \pi N d(t)}{\lambda_{0}}\right)}{1+r_{12} r_{23} \beta(t) \exp \left(-\frac{i 4 \pi N d(t)}{\lambda_{0}}\right)}(\text { Eq. } 1)
$$

where $\lambda_{0}$ is the wavelength used for monitoring at normal incidence, $d(t)$ is the thickness of film which would increase linearly versus time $(t)$ for a constant growth rate. $N=n-i k$ is the complex refractive index of materials $\left(N_{\text {GaN }}\right.$ for GaN film and $N_{s}$ for GaAs substrate). $n$ and $k$ are respectively the real part of the refractive index and the extinction coefficient of the different materials. Values for the refractive index and extinction coefficient of GaAs were taken as $n_{s}=3.86$ and $k_{s}=0.20$ [36]. The GaN optical constants ( $n$ and $k$ ) were parameters of the simulation. The refractive index of the gas-phase ambient is assumed to be equal to1. $r_{12}$ and $r_{23}$ are Fresnel reflection coefficients at interfaces $i j$ for a smooth surface film. In the virtual interface model developed by Breiland et al [37] for rough surfaces, we used the effective Fresnel coefficients, in which the modification factors $\alpha(t), \beta(t)$ and $\gamma(t)$ are related to the surface roughness $\sigma(t)$ whatever the GaAs orientation.

The real time measurable reflectance $(R(t))$ is simply obtained from the complex reflectance amplitude $r(t)$ as follows:

$$
R(t)=|r(t)|^{2} \quad(\text { Eq.2) }
$$

We adopted two profiles in the simulation model: the time-dependent surface roughness $(\sigma(t))$ and the time-dependent growth rate $(v(\mathrm{t}))$ as expressed by Eq.3 and Eq.4, respectively. The time-dependent thickness profile is deduced from the expression of $v(\mathrm{t})$, as expressed by Eq.5.

$$
\begin{gathered}
\sigma(t)=\sigma_{f}-\left(\sigma_{f}-\sigma_{i}\right) e^{\left(-\frac{\left(t-t_{i}\right)}{\tau}\right)}(\mathrm{Eq} .3) \\
v(t)=v_{f}-\left(v_{f}-v_{i}\right) e^{\left(-\frac{\left(t-t_{i}\right)}{\tau}\right)}(\mathrm{Eq} .4) \\
d(t)=d_{i}+\int_{t_{i}}^{t} v(t) d t
\end{gathered}
$$

where $\sigma_{i}$ and $v_{i}$ and $d_{i}$ are respectively the initial surface roughness, growth rate and thickness at the simulation start time $\left(t_{i}\right)$ and $\sigma_{f}$ and $v_{f}$ are their final limit values. The common coefficient in both profile parameters is the constant time $(\tau)$ which characterizes the transient regime.

Using this model, close fits of experimental data for the full set of GaN nucleation layers grown on different GaAs surface orientations were obtained. All simulations provide a standard deviation around $10^{-3}$. Simulated LR curves are shown in Fig.3 as continuous red lines. The surface roughness $\sigma(t)$ and thickness $d(t)$ profiles deduced from simulations are 
presented in the insets (a) and (b) of Fig.3, respectively. As we can see in the inset (a), whatever the substrate orientation, the surface roughness increases (regime I - nucleation) with time and then start to saturate (regime II - permanent growth) once the layer thicknesses reached values in the range of 100-200 $\mathrm{nm}$ depending on the substrate orientation. There is a little difference between the values of time constant $(\tau)$, which characterized this regime, that varies in the range of 290-310 s for the four simulated reflectance traces. The second regime is marked by limited constant values that were reached by surface roughness $\left(\sigma_{f}\right)$, which does not depend on the layer thickness but on substrate orientation. The relative surface roughness increases in the order $(001)<(111)<(112)<(113)$. Thus, the decrease of maximum contrast as well as the absolute maximum of reflectance as shown in Fig.3 is associated with light scattering effect due to surface roughness increase. From the simulations, we also found that the initial surface roughness is about 12, 10, 10 and $20 \mathrm{~nm}$ for growth on (001), (111), (112) and (113) substrate orientations, respectively. The origin of these values is assigned to the differences between surface states of nitrided substrates, as previously described by AFM images in Fig.2. From these results, we conclude that the surface roughness profiles estimated from simulations and their dependence on GaAs substrate are in good agreement with the LR curves.

The inset (b) of Fig.3 shows the time dependent thickness profiles derived from simulations. We note, for all orientations, a nonlinear increase of GaN thickness versus growth time in the regime I. This aspect can be associated to the wetting difference between $\mathrm{GaN}$ and the different GaAs substrate orientations. In the permanent growth regime (regime II), the GaN thickness linearly increases versus growth time. The difference in slopes in this regime is related to the dependence of the growth rate on the surface orientation. The lowest growth rate corresponds to (001) orientation, whereas the highest corresponds to (113) orientation. It is to be noticed that the growth rate on (111) and (112) substrate orientations are very close.

AFM images presented in Fig.4 describe the surface morphologies of LT-GaN layers grown in the temperature range $500-600{ }^{\circ} \mathrm{C}$ on the four differently oriented GaAs substrates. It is clear that both the growth temperature and substrate orientation influence the GaN layers surface morphology. For the growth on GaAs (001) substrate, the weakest roughness of the $\mathrm{GaN}$ layers is obtained for growth temperatures of 500 and $550{ }^{\circ} \mathrm{C}$. A low surface roughness is also obtained for the growth of $\mathrm{GaN}$ layers on $\mathrm{GaAs}(111)$ at $550{ }^{\circ} \mathrm{C}$. At this temperature, 
growth on GaAs (112) and GaAs (113) substrates leads to rougher surface of the GaN layers when compared to those obtained for (001) and (111) orientations. For all orientations, a growth with $3 \mathrm{D}-\mathrm{GaN}$ islands is the dominant mechanism at $570{ }^{\circ} \mathrm{C}$ which causes the drastic surface roughness increase.

Fig.5 presents the 3D plot of the rms-roughness as a function of the growth temperature and substrate orientation. In the growth temperature range of $500-570{ }^{\circ} \mathrm{C}$ a slight increase of the rms is observed whatever the substrate orientation. Indeed, at this range, the growth temperature is assumed to govern the size and density of $\mathrm{GaN}$ islands. At a growth temperature of $600^{\circ} \mathrm{C}$, the roughness of $\mathrm{GaN}$ layers is increased drastically and single large islands appear, as illustrated by the AFM images of Fig.4. This is presumably due to the fast surface migration and clustering of adatoms at higher temperatures. High growth temperature enhances the diffusion length of reactant species [38, 39], and results in the increase of the islands size formed at the beginning of growth, leading to undesirable rough surface morphology. From the section that gives RMS $\left(\varphi^{\circ}\right)$ in Fig.5, the surface roughness anisotropy can be clearly observed. This is highlighted by the change in the color as a function of offset angle at a fixed growth temperature. For example, at $550{ }^{\circ} \mathrm{C}$, we can see that the relative surface roughness increases in the order of $(001)<(111)<(112)<(113)$. The inadequate coverage of the GaAs substrates by GaN nuclei during the nitridation process can explain the difference between GaN surface morphologies obtained on the four surface orientations of the GaAs substrates.

Fig.6 shows the Arrhenius plots of the GaN nucleation layers growth rate versus the growth temperature, for each substrate orientation. The values of growth rate were extracted from SR measurements (not shown here). All Arrhenius plots show a slight slope, indicating a weak activation energy which corresponds to reaction rate limited regime. The dependence of growth rate on temperature could be associated with the morphological changes including the evolution versus growth temperature of the density and size of islands which also depend on the substrate surface orientation. The inset of Fig. 6 gives the plot of the extracted activation energies versus the offset angle $(\varphi)$. The results show an activation energy for the GaN nucleation layers grown on (113) GaAs substrate $(0.35 \mathrm{eV})$ slightly higher than that of the layers grown on (112) and (111) (0.31-0.32 eV) orientations. The lowest activation energy $(0.20 \mathrm{eV})$ is found for the layers grown on GaAs (001). This difference indicates that the $\mathrm{GaN}$ growth is kinetically influenced by the different surface reaction processes (adsorption, surface diffusion and desorption) associated with the substrate orientation. The relative 
maximum value of activation energy obtained for the (113) orientation can be explained by the highest step density in the (113) plane (see Fig.1). Compared to the atomically flatness of (001) surface, the (113) surface has corrugations due to the presence of edge steps. Since this surface has the highest step density among the (11n) surfaces [31], Ga adatoms can easily diffuse on the surface and be trapped at the closest step-edge because the mean surface diffusion lengths are usually much larger than the step spacing. Thus, surfaces with a high step density, as in the case of the (113) surface, could favor the incorporation of adatoms at the step-edges and therefore increase the reactions process at the surface leading to an increase of the activation energy.

Activation energies for the growth on (112) and (111) substrates are very close due to their comparable low nucleus density, thickness profiles, and surface morphologies of GaN layers. This similarity can be associated with the large terraces in (112) exhibiting (111) facets (see Fig.1) which partially favor in some zone the GaN growth as on GaAs (111) surface.

\subsection{Overgrowth of HT-GaN layers on the GaN nucleation layers}

It is well known that growing $\mathrm{GaN}$ at high temperature progresses its structural, electrical, optical and surface properties. However, under ammonia $\left(\mathrm{NH}_{3}\right)$ ambient and at temperature above $700^{\circ} \mathrm{C}, \mathrm{GaAs}$ substrate decomposition increased. The pre-deposition of a thin $(130 \mathrm{~nm})$ buffer layer at $550^{\circ} \mathrm{C}$ can improve the thermal stability of the GaAs substrates. GaN epitaxial sub-layers were then grown at high temperature $\left(800-900{ }^{\circ} \mathrm{C}\right)$ on the $(001)$ and $(11 \mathrm{n})$ oriented GaAs substrates. Typical growth rates were on the order of $2.55 \mu \mathrm{m} / \mathrm{h}$ and thicknesses of HT-GaN grown layers were about $0.6 \mu \mathrm{m}$.

The RT-CL spectra of GaN layers grown on (001), (113) and (112) oriented GaAs substrates are shown in fig.7 (a)-(c). The CL of the samples grown at 800 and $850{ }^{\circ} \mathrm{C}$ exhibited a broad signal in the range of $3.20-3.23 \mathrm{eV}$ whatever the substrate orientation as expected for the excitonic recombinations in cubic GaN [41]. The CL intensity of cubic GaN layers grown at $850^{\circ} \mathrm{C}$ is about two orders of magnitude higher than those elaborated at $800^{\circ} \mathrm{C}$. This is certainly attributed to the crystallization of $\mathrm{GaN}$ on the surface. We clearly noted from figures 7 (a) and 7 (b) the absence of the CL emission of h-GaN peaks at around $3.4 \mathrm{eV}$. As the growth temperature rises to $900{ }^{\circ} \mathrm{C}$ (fig.7 (c)), the CL-peaks are shifted towards high energy: 3.29, 3.33, 3.39 and $3.38 \mathrm{eV}$ for (001), (113), (112) and (111) GaAs substrate orientations, respectively. This behavior is in connection with the increase of the 
amount of hexagonal phase inclusions in the c-GaN films. In fact, the increase of growth temperature leads to the incorporation of hexagonal $\mathrm{GaN}$ domains due to the generation of planar defects (stacking faults) at the GaN/GaAs interface [42]. The CL peak of each orientation obtained at $900{ }^{\circ} \mathrm{C}$ are an overlap of broad peaks of the transitions in h-GaN and some excitonic recombinations in c-GaN. By dividing the corresponding integrated $\mathrm{CL}$ intensities, as seen in fig.7 (c), the emission from cubic CL is still observable for all used GaAs substrates orientations.

In fig.7 (d), we present the variation of the ratio of h-GaN to the c-GaN intensity as a function substrate orientation. This ratio can reflect the fraction of the $\mathrm{h}-\mathrm{GaN}$ inclusions in c$\mathrm{GaN}$. It can be seen that the hexagonal inclusions are just a few percent for the growth on (001) and (113) GaAs substrates orientations while in the case of growth on (112) and (111) orientations, the hexagonal phase is still dominant. These results indicate that we have hexagonal GaN structure on (112) and (111) orientations and a mixture (cubic and hexagonal) GaN structure on (001) and (113) orientations. The high fraction of h-GaN inclusions can be associated with the surface structure of (112) and (111) GaAs substrates exhibiting a large (111) facets which favor the presence of the stacking faults (SFs). When the SFs have been generated at high density in some localized areas, a cubic-to-hexagonal phase transformation domains in GaN layers was observed [43].

As we conclude, both (111) facets in the GaAs surface and a high growth temperature favor the GaN growth with hexagonal structure, whereas the GaN cubic structure is favored at a low growth temperature on (001) and (113) GaAs substrates orientations. Theses surfaces would appear to be the best surfaces for the subsequent c-GaN epitaxy and device structure.

\section{Conclusion}

We investigated the LT-GaN growth on (001) and high index GaAs substrates. The effects of these orientations on growth kinetics were discussed. At $550^{\circ} \mathrm{C}$, the time-reflectance of GaN varied greatly with crystallographic orientation of GaAs substrate. The simulations of time-reflectance showed the dependence of GaN surface morphology and growth rate on substrate orientation. These results were supported by ex situ AFM and SR analyses. The growth on the (113) oriented GaAs substrate was characterized by the high activation energy. The dependence of growth rate activation energy on crystallographic orientation indicates the dependence of the GaN growth on substrate orientation. The similarity in terms of growth 
kinetics and crystalline structure between results obtained on (112) and (111) orientations could be associated with the large (111) terraces in (112) surface. CL studies show that both (111) surface GaAs substrate and a high growth temperature $\left(>850^{\circ} \mathrm{C}\right)$ favor the $\mathrm{GaN}$ hexagonal structure, whereas the GaN cubic is favored at a low growth temperature on (001) surface GaAs substrate.

\section{Acknowledgements}

This work is supported by an ARUBE program of DGRST.

\section{References}

[1] B. Gill, III-Nitride Semiconductors and Their Modern Devices, Oxford University Press, UK (2013).

[2] S. Nakamura, G. Fasol, The blue laser diode, Springer (1997)

[3] H. Bouazizi , N. Chaaben , Y. El Gmili , A. Bchetnia, J.P. Salvestrini, B. El Jani, Journal of Crystal Growth 434 (2016) 72.

[4] S. Qua, S. Li, Y. Penga, X. Zhub, X. Hua, C. Wang, X. Chena, Y. Gaoa, X. Xu, Journal of Alloys and compounds 502 (2010) 417.

[5] I. H. Oğuzman, E. Bellotti, K. F. Brennan, Journal of Applied Physics 81 (1997) 7827.

[6] H. Vilchis, V. M. Sanchez-R, Materials Science in Semiconductor Processing 37 (2015) 68.

[7] D. Xu, H. Yang, J. B. li, S. F. Li, Y. T. Wang, D. G. Zhao, R. H. Wu, Journal of Crystal Growth 206 (1999) 150.

[8] H. Chen, Z. Q. Li, H. F. Liu, L. Wan, M. H. Zhang, Q. Huang, J. M. Zhou, Y. Luo, Y. J. Han, K. Tao, N. Yang, Journal of Crystal Growth 210 (2000) 811.

[9] B. Yang, O. Brandt, A. Trampert, B. Jenichen, K. H. Ploog, Applied Surface Science 123 (1998) 1.

[10] T. Onuma, T. Nozaka, H. Yamaguchi, T. Suzuki, S. F. Chichibu, Journal of Crystal Growth 298 (2007) 193.

[11] H. Tachibana, T. Ishido, M. Ogawa, M. Funato, S. Fujita, S. Fujita, Journal of Crystal Growth 196 (1999) 41.

[12] Z. X. Qin, H. Nagano, Y. Sugure, A. W. Jia, M. Kobayashi, Y. Kato, A. Yoshikawa, K. Takahashi, Journal of Crystal Growth 189 (1998) 425.

[13] A. Nakadaira, H. Tanaka, Journal of Crystal Growth 189/190 (1998) 411. 
[14] J. Wu, F. Zhao, K. Onabe, Y. Shiraki, Journal of Crystal Growth 221 (2000) 276.

[15] H. Vilchis, V. M. Sanchez, A. Escobosa, Thin Solid Films 520 (2012) 5191.

[16] R. Nötzel, D. Eissler, K. Ploog, Journal of Crystal Growth 127 (1993) 1068.

[17] K. Jacobi, L. Geelhaar, J. Marquez, Applied physics A 75 (2002) 113.

[18] H. Fitouri, I. Moussa, A. Rebey, B. El Jani, Journal of Crystal Growth 300 (2007) 347.

[19] W. Ono, F. Nakajima, S. Sanorpim, R. Katayama, K. Onabe, Journal of Crystal Growth 298 (2007) 135.

[20] A. Khatab, O. M. Lemine, A. Alkaoud, A. Falamas, M. Aziz, Y. Galvão Gobatod, M. Henini, Physica E 54 (2013) 233.

[21] I. Zaied, H. Fitouri, Z. Chine, A. Rebey, B. El Jani, Journal of Physics and Chemistry of solids 75 (2014) 244.

[22] R. Notzel, N. N. Ledentsov, L. Daweritz, K. Ploog, M. Hohenstein, Physical Review B 45 (1992) 3507.

[23] W. I. Wang, E. E. Mendez, Y. Iye, B. Lee, M. H. Kim, G. E. Stillman, Journal of Applied physics 60 (1986) 1834.

[24] M. Henini, A. Polimeni, A. Patane, L. Eavesa, P.C. Maina, G. Hill, Microelectronics Journal, 30 (1999) 319.

[25] T. Makimoto, M. Kasu, J. L. Benchimol, N. Kobayashi, Japanese Journal of Applied Physics 36 (1997) 1733.

[26] M. Funato, Sz. Fujita, S. Yamamoto, K. Kaisei, K. Shimogami, SG. Fujita, Physica Status Solidi (a) 188 (2001) 543.

[27] S. Sanorpim, N. Discharoen, K. Onabe, Physica Status Solidi (c) 7 (2010) 2076.

[28] O. Brandt, H. Yang, H. Kostial, K. H. Ploog, Applied Physics Letters 69 (1996) 2707.

[29] P. Saengkaew, S. Sanorpim, V. Yordsri, C. Thanachayanont, K. Onabe, Journal of Crystal Growth 411 (2015) 76.

[30] M. Wassermeier, J. Sudijono, M. D. Johnson, K. T. Leung, B. G. Orr, L. Daweritz, K. Ploog, Journal of Crystal Growth 150 (1995) 425.

[31] M. Konodo, C. Anayama, N. Okada, H. Sekiguchi, K. Domen, Journal of Applied Physics 76 (1994) 914.

[32] C. Messmer, J. C. Bilello, Journal of Applied Physics 52 (1981) 4623.

[33] J. Platen, A. Kley, C. Setzer, K. Jacobi, P. Ruggerone, M. Scheffler, Journal of Applied Physics 85 (1999) 3597.

[34] C. Liu, I. M Watson, Semiconductor Science and Technology 22 (2007) 629. 
[35] N. Chaaben, H. Bouazizi, C. Saidi, A. Bchetnia, B. El Jani, Superlattices and Microstructures 64 (2013) 518.

[36] D. E. Aspnes, A. A. Studna, Physical Review B 27 (1983) 985.

[37] W. G. Breiland, K. P. Killeen, Journal of Applied Physics 78 (1995) 6726.

[38] D. Xu, H. Yang, J. B. Li, S. F. Li, Y. T. Wang, D. G. Zhao, R. H. Wu, Journal of Electronic Materials 29 (1999) 177.

[39] K. Wang, D. Pavlidis, Jasprit Singh, Journal of Applied Physics 80 (1996) 1823.

[41] N. Zainal, S. V. Novikov, A. V. Akimov, C. R. Staddon, C. T. foxon, A. J. Kent, Physica B 407 (2012) 2964.

[42] S. Suandon, S. Sanoprim, K. Yoodee, K. Onabe, Thin Solid Films 515 (2007) 4393.

[43] S. N. Waheeda, N. Zainal, Z. Hassan, S. V. Novikov, A. A. Akimov, A. J. kent, Applied Surface Science 317 (2014) 1010.

\section{Figures captions}

Figure 1: Representation of (001) plane and high index planes of GaAs surface. The open and solid circles represent Ga and As atoms, respectively.

Figure 2: AFM images at a scale of $\left(5 \times 5 \mu \mathrm{m}^{2}\right)$ of nitrided GaAs substrates for $10 \mathrm{~min}$ at $550^{\circ} \mathrm{C}$ : (a) (001), (b) (113), (c) (112) and (d) (111).

Figure 3: Plots of experimental reflectance data (Scatters) and simulations (solid lines) data corresponding to samples grown on (001), (111), (112) and (113) GaAs substrates. All experimental reflectances are horizontally translated to have the same start time $\left(\mathrm{t}_{\mathrm{i}}\right)$ when TMG is run and normalized to the substrate one (Rs). The inset (a) and (b) show the plots of surface roughness and thickness profiles, respectively, giving the best fit of experimental reflectance data.

Figure 4: AFM images of GaN layers grown on different substrate orientations at growth temperature of $500^{\circ} \mathrm{C}, 550^{\circ} \mathrm{C}, 570^{\circ} \mathrm{C}$ and $600^{\circ} \mathrm{C}$. Horizontally: evolution of the surface morphology as a function of growth temperature for each crystalline orientation. Vertically: differences in morphology according to the crystallographic orientation of substrate for each temperature.

Figure 5: 3D-Plot of surface roughness as a function of the offset angle $(\varphi)$ and growth temperature. 
Figure 6: Growth rate evolution of $\mathrm{GaN}$ layers grown on different GaAs substrate orientations versus reverse of temperature. The solid line indicates the linear fit. The inset shows the activation energy evolutions versus the offset angle $(\varphi)$.

Figure 7: (a)-(c) RT-CL spectra of GaN layers grown at high growth temperatures in the range of $800-900{ }^{\circ} \mathrm{C}$ on $\mathrm{GaN}$ buffer layers grown at $550^{\circ} \mathrm{C}$ on $(001)$ and $(11 \mathrm{n})$ oriented $\mathrm{GaAs}$ substrates. The dashed line in fig.7 (c) shows the Gaussian fitting to the measured data. Fig.7 (d) shows the variation of the ratio of $\mathrm{h}-\mathrm{GaN}$ to the $\mathrm{c}-\mathrm{GaN}$ intensity as a function of substrate orientation. 


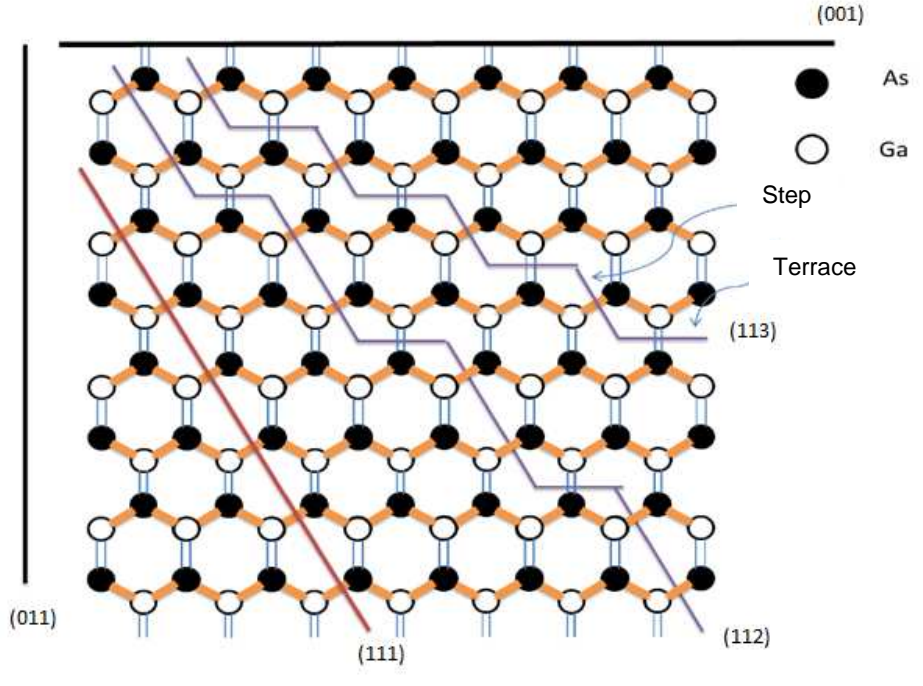

Fig.1
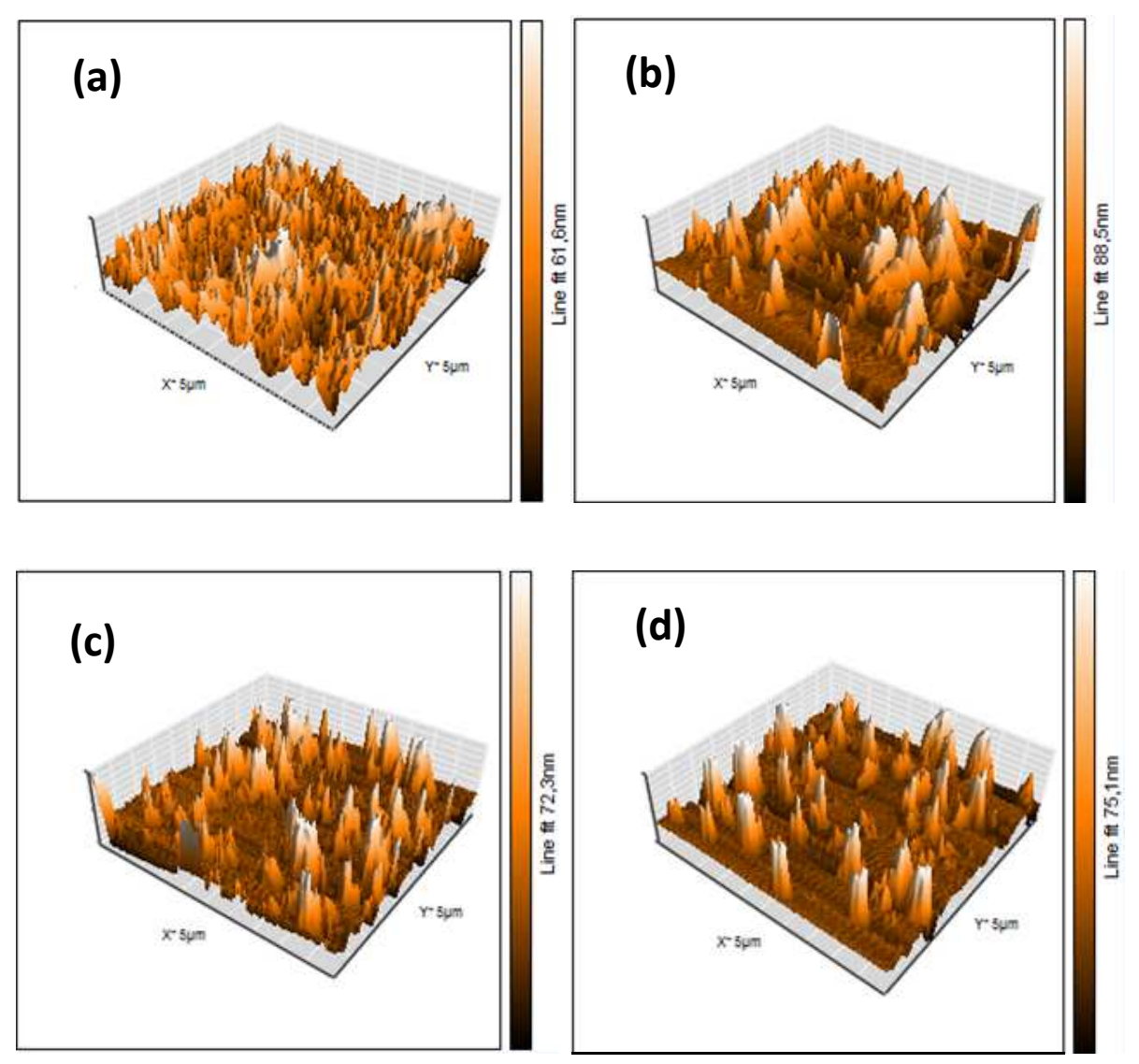

Fig.2 


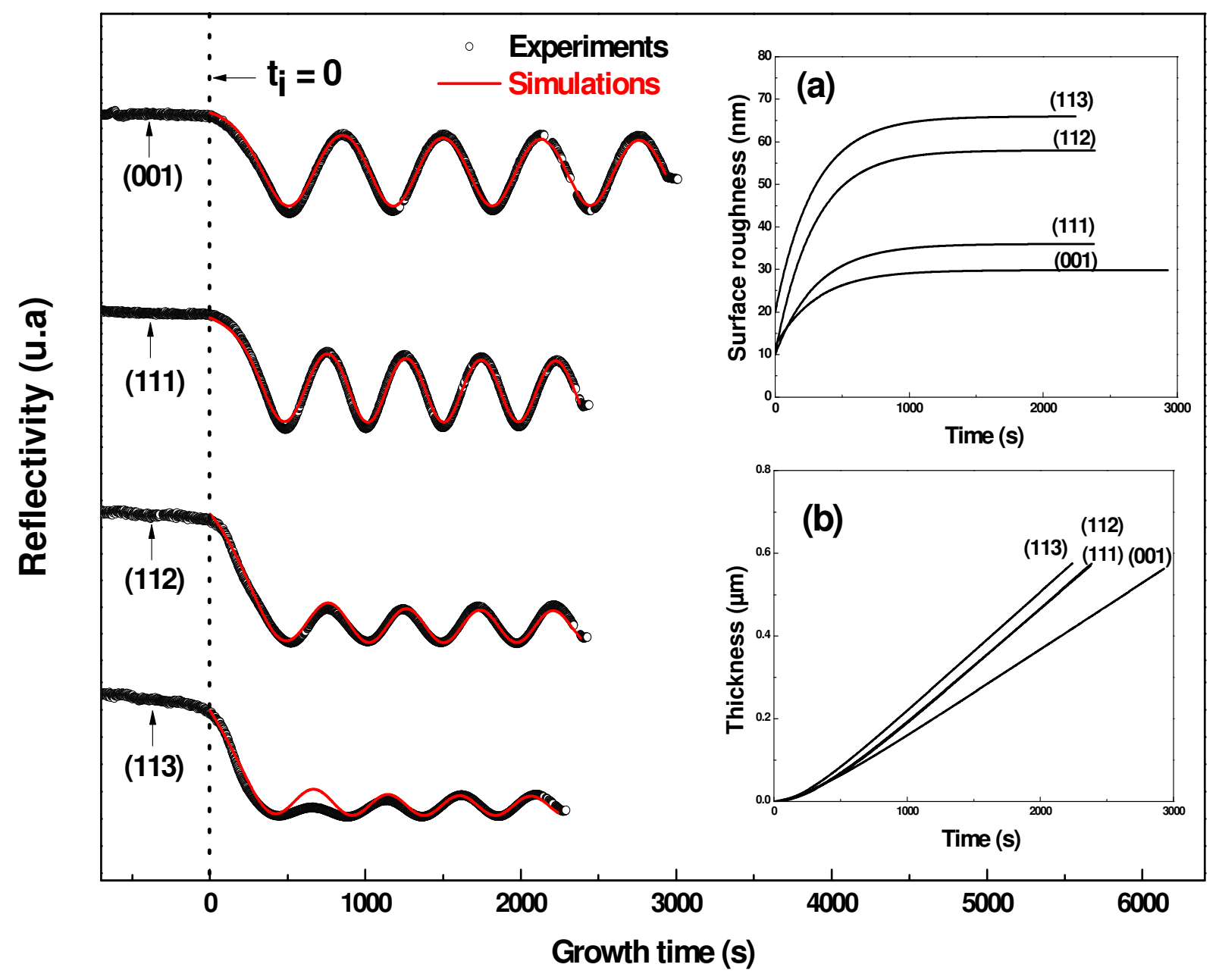

Fig.3 

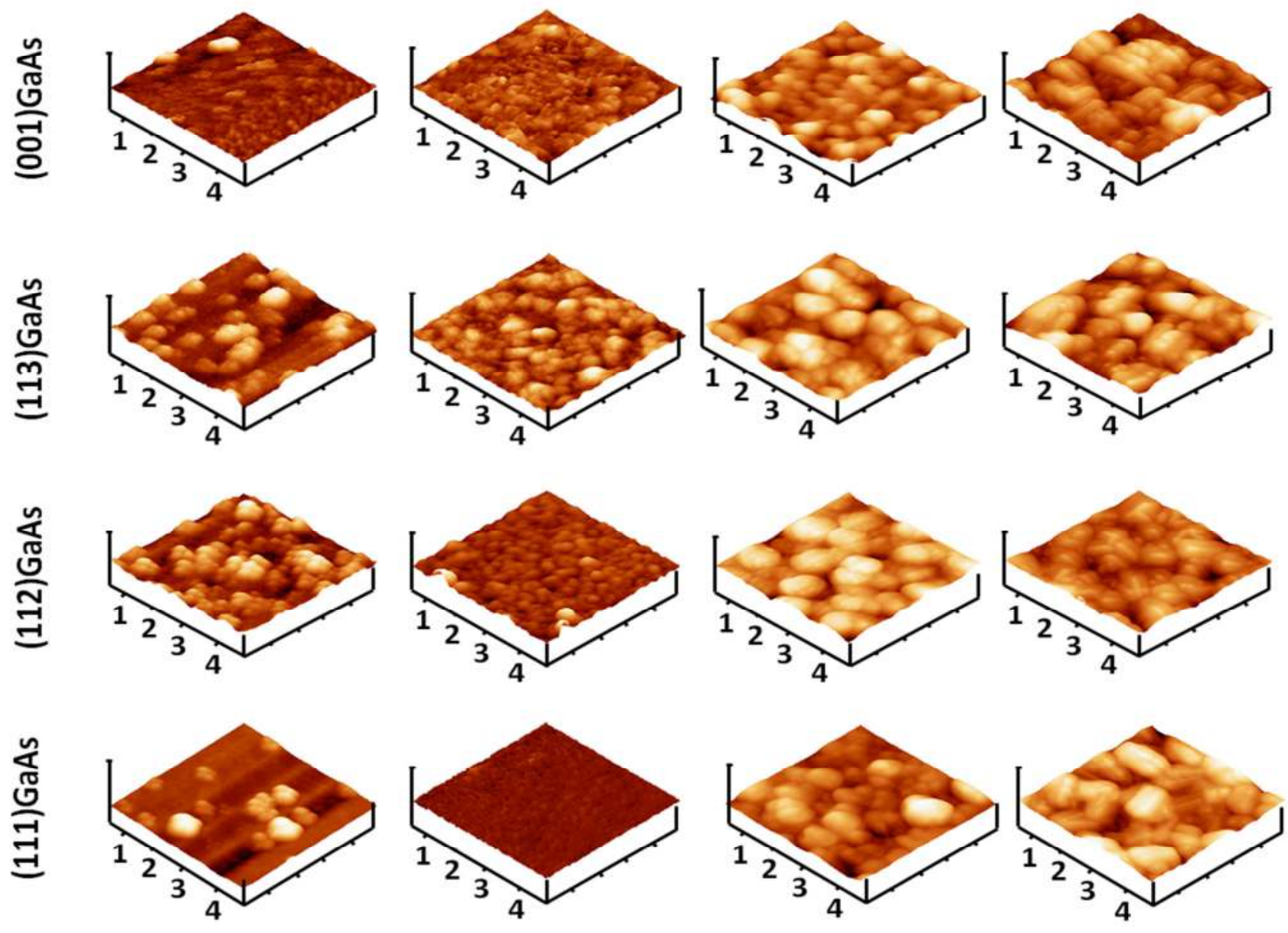

$\mathrm{T}=500^{\circ} \mathrm{C}$

$\mathrm{T}=550^{\circ} \mathrm{C}$

$\mathrm{T}=575^{\circ} \mathrm{C}$

$\mathrm{T}=600^{\circ} \mathrm{C}$

Fig.4 


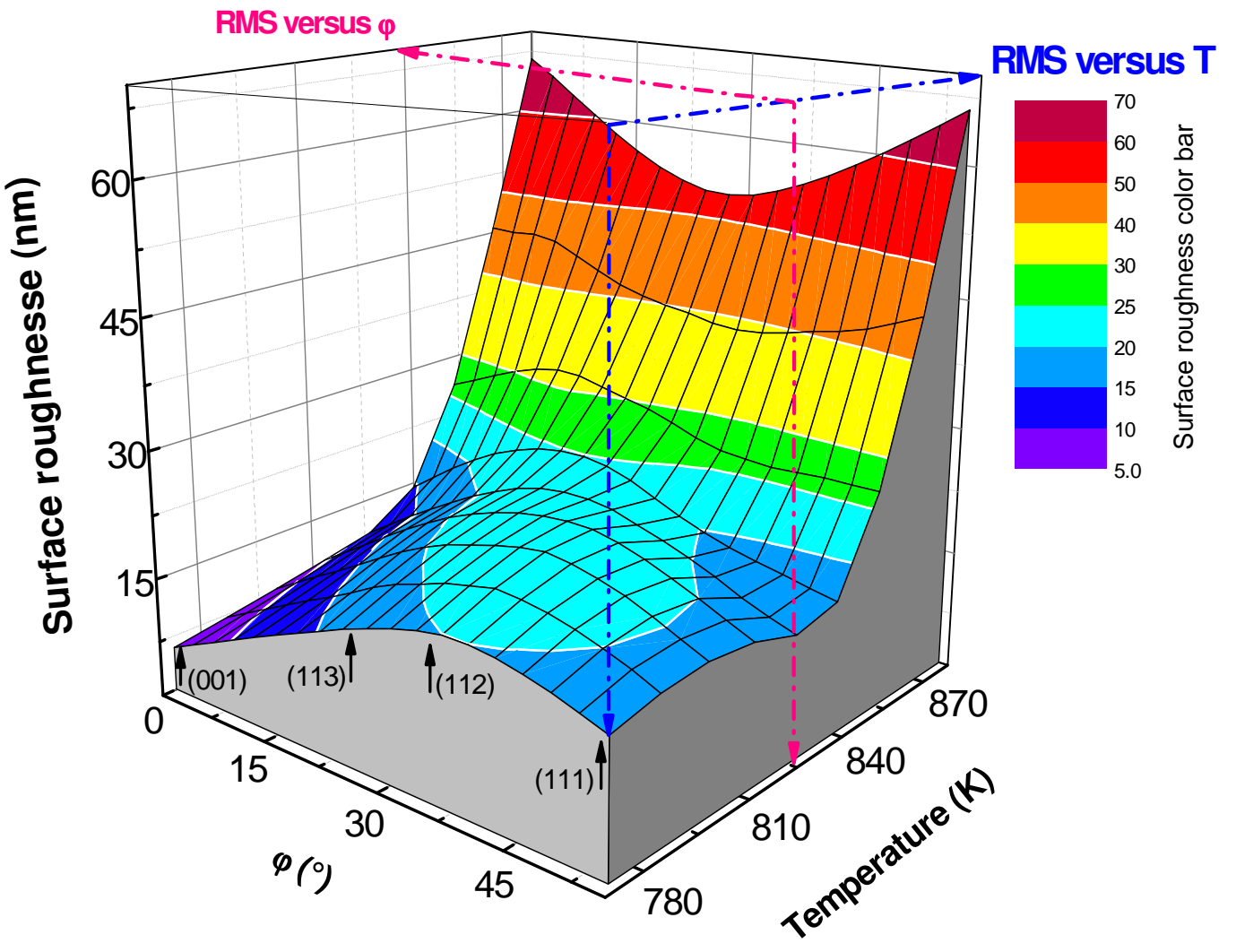

Fig.5 


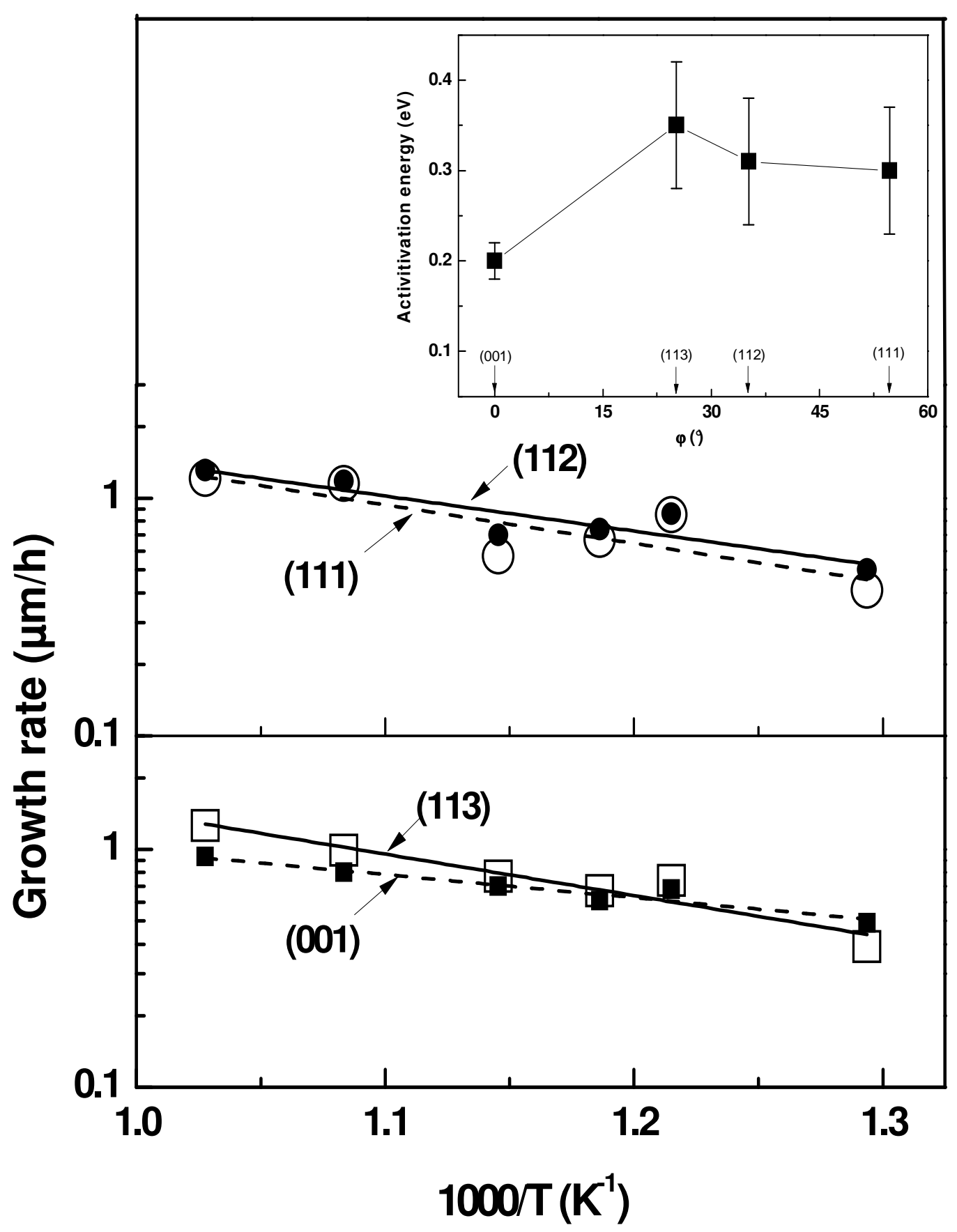

Fig.6 

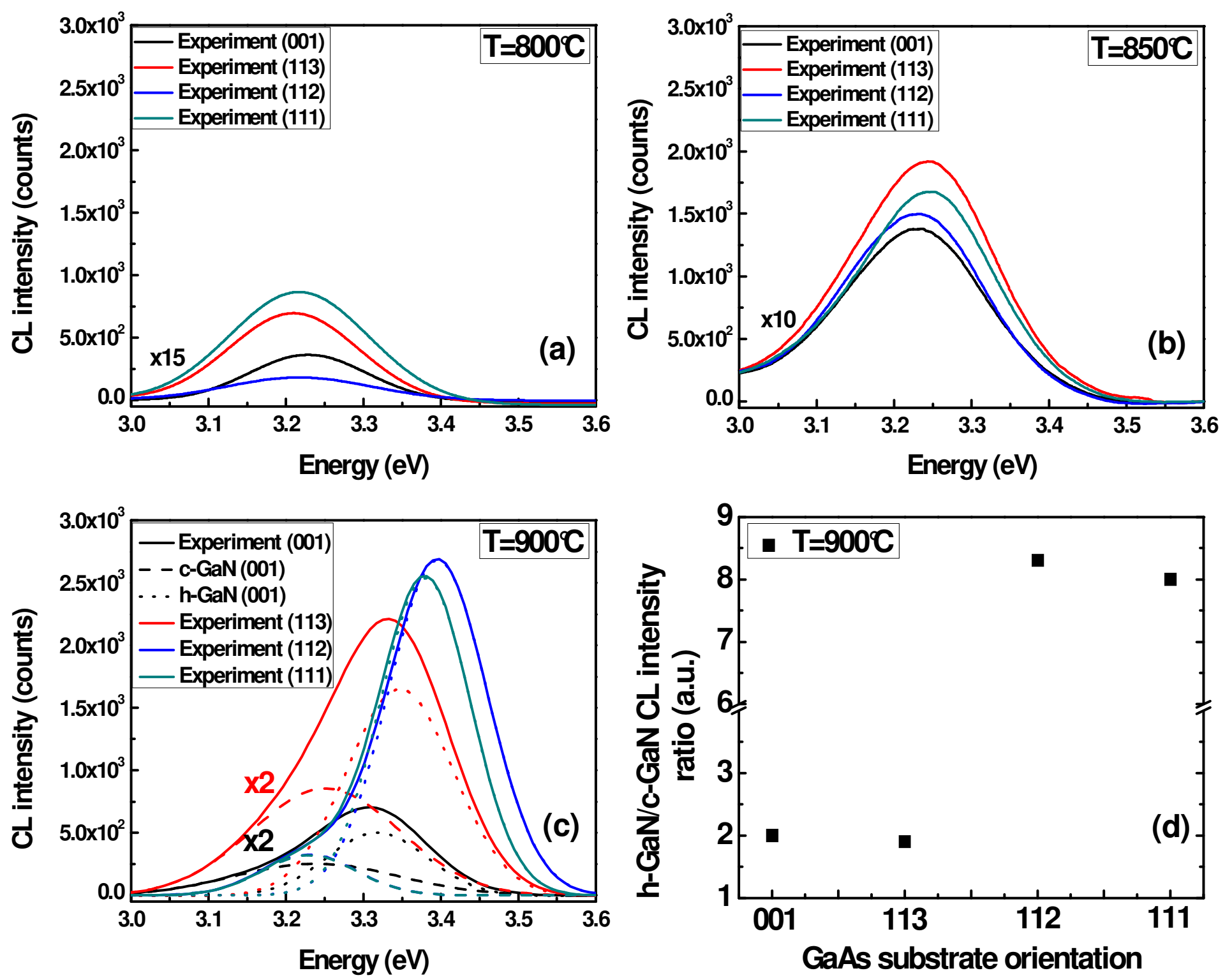

Fig.7 


\section{Highlights}

- The epitaxial growth of GaN films on (001) and high index GaAs substrates have been investigated.

- The simulations of the time-reflectance have showed the dependence of GaN surface morphology and growth rate on substrate orientation and growth temperature.

- The growth rate activation energy dependence on crystallographic orientation indicates anisotropy of GaN growth.

- Cathodoluminescence (CL) studies show that the transition from cubic to hexagonal structures is dependent on the growth temperature and substrate orientation. 